\title{
CAUSES AND OUTCOMES OF THE ACUTE CHEST SYNDROME IN SICKLE CELL DISEASE
}

\author{
Elliott P. Vichinsky, M.D., Lynne D. Neumayr, M.D., Ann N. Earles, R.N., P.N.P., Roger Williams, M.D., \\ Evelyne T. Lennette, Ph.D., Deborah Dean, M.D., M.P.H., Bruce Nickerson, M.D., Eugene OrRinger, M.D., \\ Virgil McKie, M.D., Rita Bellevue, M.D., Charles Daeschner, M.D., ANd Elizabeth A. Manci, M.D., \\ for the National Acute Chest Syndrome Study Group*
}

\begin{abstract}
Background The acute chest syndrome is the leading cause of death among patients with sickle cell disease. Since its cause is largely unknown, therapy is supportive. Pilot studies with improved diagnostic techniques suggest that infection and fat embolism are underdiagnosed in patients with the syndrome.

Methods In a 30-center study, we analyzed $671 \mathrm{ep}-$ isodes of the acute chest syndrome in 538 patients with sickle cell disease to determine the cause, outcome, and response to therapy. We evaluated a treatment protocol that included matched transfusions, bronchodilators, and bronchoscopy. Samples of blood and respiratory tract secretions were sent to central laboratories for antibody testing, culture, DNA testing, and histopathological analyses.
\end{abstract}

Results Nearly half the patients were initially admitted for another reason, mainly pain. When the acute chest syndrome was diagnosed, patients had hypoxia, decreasing hemoglobin values, and progressive multilobar pneumonia. The mean length of hospitalization was 10.5 days. Thirteen percent of patients required mechanical ventilation, and 3 percent died. Patients who were 20 or more years of age had a more severe course than those who were younger. Neurologic events occurred in 11 percent of patients, among whom 46 percent had respiratory failure. Treatment with phenotypically matched transfusions improved oxygenation, with a 1 percent rate of alloimmunization. One fifth of the patients who were treated with bronchodilators had clinical improvement. Eighty-one percent of patients who required mechanical ventilation recovered. A specific cause of the acute chest syndrome was identified in 38 percent of all episodes and 70 percent of episodes with complete data. Among the specific causes were pulmonary fat embolism and 27 different infectious pathogens. Eighteen patients died, and the most common causes of death were pulmonary emboli and infectious bronchopneumonia. Infection was a contributing factor in 56 percent of the deaths.

Conclusions Among patients with sickle cell disease, the acute chest syndrome is commonly precipitated by fat embolism and infection, especially community-acquired pneumonia. Among older patients and those with neurologic symptoms, the syndrome often progresses to respiratory failure. Treatment with transfusions and bronchodilators improves oxygenation, and with aggressive treatment, most patients who have respiratory failure recover. (N Engl J Med 2000;342:1855-65.)

(C2000, Massachusetts Medical Society.
$\mathrm{T}$ HE acute chest syndrome is the leading cause of death and hospitalization among patients with sickle cell disease. ${ }^{1-3}$ The optimal treatment has not been established because the cause remains largely unknown. Both infectious and noninfectious causes have been described, but their frequency and clinical course are unknown. ${ }^{4-12}$ Pulmonary fat embolism has been identified during autopsies and in studies examining fatladen pulmonary macrophages from bronchoalveolar fluid. ${ }^{4,11-13}$ However, the number of patients included in these reports is too small for general recommendations to be made. ${ }^{11}$

Appropriate therapy remains controversial. The antibiotics used are based on organisms identified decades ago, and data regarding the use of new antibiotics for emerging pathogens are limited. Antiviral treatments have not been carefully studied in patients with sickle cell disease. Furthermore, the benefit of transfusion and bronchodilator therapy has not been clearly established.

In 1993, we initiated a prospective, multicenter study of the acute chest syndrome in order to determine the causes, incidence, and clinical outcome of the syndrome and factors that predict prognosis.

\section{METHODS}

\section{Patients}

Patients were enrolled at 30 centers. Each institution had a principal investigator, data coordinator, pulmonologist, and nurse assigned to the study. Patients were enrolled after they or their parents or guardians provided written informed consent. The in-

From the Departments of Hematology-Oncology (E.P.V., L.D.N., A.N.E.) and Pathology (R.W.), Children's Hospital Oakland, Oakland, Calif.; Virolab, Berkeley, Calif. (E.T.L.); the Department of Medicine, University of California School of Medicine at San Francisco, San Francisco (D.D.); the Department of Pediatric Pulmonary Medicine, Children's Hospital of Orange County, Orange, Calif. (B.N.); the Department of Hematology, University of North Carolina, Chapel Hill (E.O.); the Department of Pediatric Hematology-Oncology, Medical College of Georgia, Augusta (V.M.); the Department of Medicine, New York Methodist Hospital, Brooklyn (R.B.); the Department of Pediatric Hematology-Oncology, East Carolina University, Greenville, N.C. (C.D.); and the Department of Pathology, University of Southern Alabama Doctors' Hospital, Mobile (E.A.M.). Address reprint requests to Dr. Vichinsky at Children's Hospital Oakland, 747-52nd St., Oakland, CA 94609, or at evichinsky@mail.cho.org.

Other authors were Miguel Abboud, M.D. (Medical University of South Carolina, Charleston); Mark Moncino, M.D. (Scottish Rite Children's Medical Center, Atlanta); Samir Ballas, M.D. (Thomas Jefferson University, Philadelphia); and Russell Ware, M.D. (Duke University Medical Center, Durham, N.C.).

* Other members of the National Acute Chest Syndrome Study Group are listed in the Appendix. 
stitutional review board at each participating center approved the study. To be eligible, patients had to have a phenotype of hemoglobin SS, hemoglobin SC, or hemoglobin SS $-\beta$-thalassemia on electrophoretic analysis of the hemoglobin chains and to have had an episode of the acute chest syndrome. The acute chest syndrome was defined on the basis of the finding of a new pulmonary infiltrate involving at least one complete lung segment that was consistent with the presence of alveolar consolidation, but excluding atelectasis. In addition, the patients had to have chest pain, a temperature of more than $38.5^{\circ} \mathrm{C}$, tachypnea, wheezing, or cough.

From March 1993 through March 1997, 721 episodes of the acute chest syndrome were reported. Fifty episodes were excluded: 30 because of missing forms, and 20 because of diagnostic error and withdrawal from the study. Data were available on 671 episodes in 538 patients, including 443 patients with a single episode and 95 with recurrent episodes $(69$ with two episodes, 16 with three episodes, 8 with four episodes, and 2 with five episodes).

\section{Treatment Protocol and Data Collection}

A standardized treatment and monitoring protocol was used (Fig. 1). Transfusion guidelines included the use of units that were depleted of leukocytes, negative for sickle cells, and matched with respect to Rh C and E antigens and Kell antigens. Patients were monitored for alloantibodies by standard tests at enrollment, before and after each transfusion, and at follow-up. Patients received transfusions to improve respiratory status at the discretion of their physicians. Standardized forms were used to document medical history, findings on daily physical examinations, findings on radiography, oxygenation status, the need for transfusions, complications of bronchoscopy, and findings on follow-up.

\section{Laboratory Studies and Diagnostic Criteria}

Blood for culture was obtained before therapy whenever possible. Bronchoscopy was performed to obtain samples for aerobic and anaerobic cultures and for the fat embolism assay. In patients who did not undergo bronchoscopy, sputum was collected either after the inhalation of aerosolized saline or by tracheal aspiration. ${ }^{11}$ A bacterial cause of the acute chest syndrome was identified on the basis of a positive blood culture or heavy growth of an organism in a bronchial culture with confirmatory results on Gram's staining.

Bronchial and nasopharyngeal samples were used for standard viral cultures ${ }^{14}$ and cultures for mycoplasma were performed with use of SP4 and A8 mediums. ${ }^{15}$ All viral and mycoplasma isolates were identified by immunofluorescence staining with specific reagents. Legionella pneumophila serogroups 1 through 6 were detected by indirect immunofluorescence staining.

Serum samples were collected during the acute phase of illness and during convalescence; the median interval between sample collection was 48 days. An increase in antibody titers by a factor of at least 4 during this interval was used to diagnose Mycoplasma pneumoniae, ${ }^{16}$ parvovirus B19, ${ }^{17}$ and Epstein-Barr virus. ${ }^{18}$ Increases were confirmed by specific IgM antibody tests.

In a subgroup of patients, pairs of serologic samples and bronchoscopic or sputum samples were sent to the laboratory of Dr. Julias Schachter (University of California, San Francisco) for culture for chlamydia and for measurement of chlamydia antibody titers according to the microimmunofluorescence technique. ${ }^{19} \mathrm{Na}-$ sopharyngeal samples were further analyzed by the polymerase chain reaction..$^{20}$ The diagnosis of Chlamydia pneumoniae infection was based on an increase in IgG antibody titers by a factor of 4 in the absence of cross-reactivity with C. trachomatis on microimmunofluorescence analysis, an initial $\operatorname{IgM}$ antibody titer of more than $1: 16$, or a positive polymerase-chain-reaction assay.

Intracellular lipid from alveolar macrophages obtained from bronchial samples was evaluated for evidence of pulmonary fat embolism according to a modification of the Corwin index, a method for quantification of the amount of lipid found in pulmonary macrophages. ${ }^{11}$ Samples obtained at autopsy and histopathological slides were analyzed by the central pathology unit for evidence of sickle cell disease.

\section{Statistical Analysis}

We performed inferential statistical analyses after eliminating all but the first episode of the acute chest syndrome for each patient. For comparisons of clinical data among age groups, we compared proportions using chi-square analysis with Yates' correction or Fisher's exact test. All confidence intervals were two-sided, and a P value of 0.05 or less was considered to indicate statistical significance. For comparison of means, we used Student's t-test or analysis of variance; results are reported as means $\pm \mathrm{SD}$. When assumptions for parametric analyses were not met, the Wilcoxon rank-sum test was used. When summarizing data concerning causation, we included all episodes.

We developed a Cox proportional-hazards regression model for the duration of hospitalization in which we reduced age and 40 other variables from the patients' medical history and hospital course to 19 covariates that were significant on univariate analyses. These variables were included in a multivariable proportional-hazards regression model designed to identify factors that were independently associated with the time of discharge from the hospital. Data on patients were censored at the time of death, and one variable for which more than 20 percent of values were missing was not entered into the model.

Multivariable logistic-regression models were developed for the presence or absence of respiratory failure and neurologic complications in order to identify predictors of these events at the time of diagnosis. We performed univariate logistic-regression analyses of these outcomes and 35 clinical variables of interest. Only clinical variables that were significantly related in the univariate analyses to the outcome variable were included in the multivariable logisticregression model.

\section{RESULTS}

\section{Diagnosis and Symptoms of the Acute Chest Syndrome at Admission}

The characteristics of the patients are summarized in Table 1. Data on one patient (one episode) were excluded because the patient's birth date was not known. Nearly half the patients were admitted with a diagnosis other than the acute chest syndrome; 72 percent of these patients were admitted because of a vaso-occlusive crisis. Among patients who were not admitted for the acute chest syndrome, radiographic and clinical findings of the syndrome appeared a mean of 2.5 days after admission. The symptoms at presentation varied with age (Table 1 ).

\section{Hospital Course and Treatment}

The findings on physical and radiographic examination are summarized in Table 2. During hospitalization, multilobar involvement, especially of the lower lobes, was common in all age groups, and effusion was present in 55 percent of all patients. All patients were treated with antibiotics and, on average, became afebrile after a mean of two days of hospitalization.

At diagnosis, the mean oxygen saturation was 92 percent while the patients were breathing room air. There was no significant difference in the extent of hypoxia among the age groups, but younger patients were less likely to be treated with oxygen and mechanical ventilation. Thirteen percent of all patients required mechanical ventilation, and the mean duration of mechanical ventilation was 4.6 days. Eightyone percent of the patients who required mechanical ventilation recovered. 


\section{Treatment}

Oxygen therapy required for patients with a partial pressure of arterial oxygen of less than $60 \mathrm{~mm} \mathrm{Hg}$ or oxygen saturation of less than 90 percent.

Antibiotic therapy, consisting of cephalosporin and erythromycin intravenously until fever had been absent for at least 24 hours and then orally, for a total of 7 to 10 days, given to all patients.

Fluid management individualized on the basis of cardiopulmonary status. 1 to $1 \frac{1}{2}$ times daily fluid requirements (intravenous plus oral), with modifications based on daily weight and intake and output analysis.

Respiratory therapy consisting of incentive-spirometry protocol for all patients who were able to perform it.

Pain-management protocol included guidelines for patient-controlled analgesia and dosages of narcotics and nonsteroidal agents, with the goal being to prevent respiratory splinting and avoid hypoventilation and narcosis; cardiorespiratory monitoring was continuous.

Bronchodilator therapy given to patients with evidence of reactive airway disease.

Transfusion therapy given to patients for clinical distress, at physician's discretion.

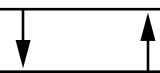

\section{Laboratory Monitoring}

Daily blood count, serial chemistry panels.

Pretransfusion and post-transfusion studies, including concentrations of hemoglobin $\mathrm{S}$ and partial pressure of oxygen.

Continuous (or every 8 hours) pulse oximetry.

Daily arterial-blood gas measurements until partial pressure of arterial oxygen was $75 \mathrm{~mm} \mathrm{Hg}$ or greater while patient was breathing room air.

Daily chest radiography until improvement was documented.

Pulmonary-function tests at onset of episode, at discharge, and at the 6-week follow-up visit in patients who were able to participate.

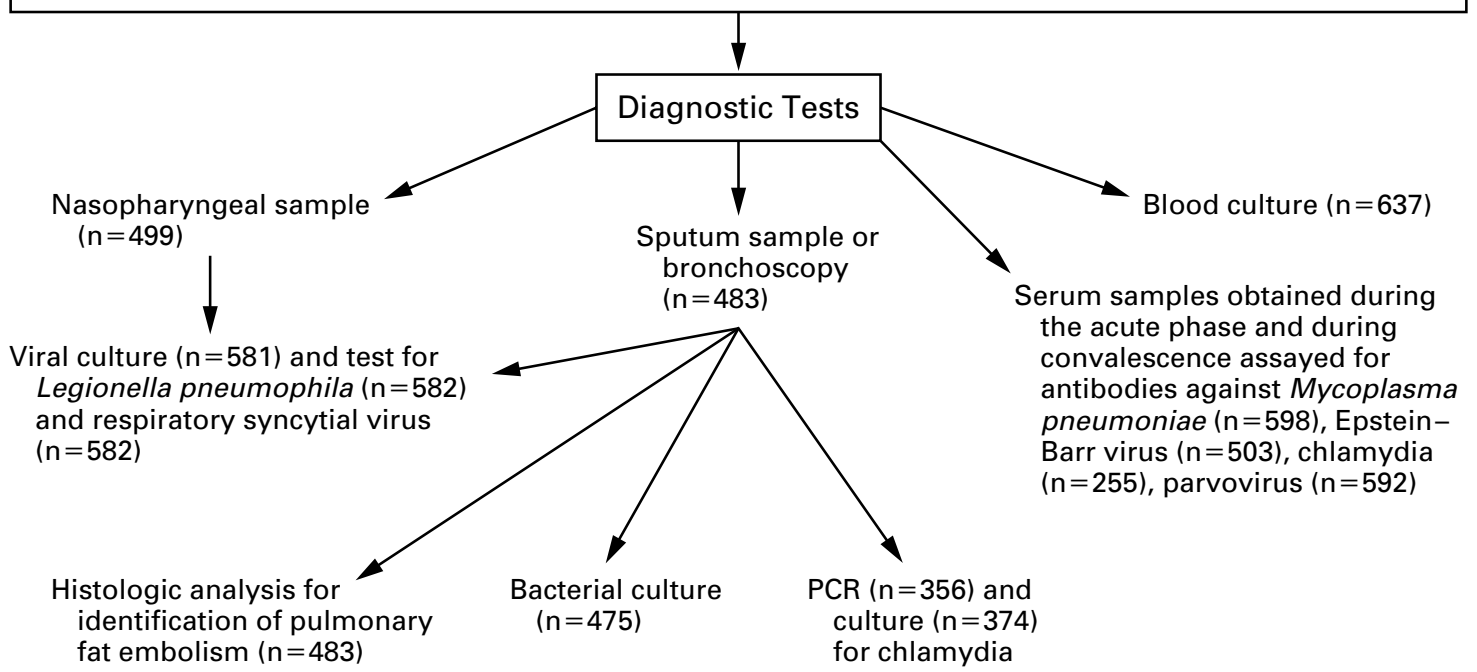

Figure 1. Protocol for Treatment and Monitoring.

PCR denotes polymerase chain reaction. The numbers in parentheses are the numbers of episodes. 
Table 1. Characteristics of the Patients.*

\begin{tabular}{|c|c|c|c|c|c|}
\hline \multirow[t]{2}{*}{ CHARACTERISTIC } & \multirow[t]{2}{*}{$\begin{array}{c}\text { ALL } \\
\text { PATIENTS } \\
(\mathrm{N}=537)\end{array}$} & \multicolumn{3}{|c|}{$\begin{array}{l}\text { AgE at FirSt EPISODE OF ACUTE } \\
\text { Chest SYNDRome }\end{array}$} & \multirow[t]{2}{*}{$\begin{array}{c}P \\
\text { VALUE† }\end{array}$} \\
\hline & & $\begin{array}{c}0-9 \text { YR } \\
(\mathrm{N}=264)\end{array}$ & $\begin{array}{l}10-19 \text { YR } \\
(\mathrm{N}=145)\end{array}$ & $\begin{array}{l}\geqslant 20 \mathrm{YR} \\
(\mathrm{N}=128)\end{array}$ & \\
\hline \multicolumn{6}{|l|}{$\operatorname{Sex}(\%)$} \\
\hline Male & 58 & 63 & 57 & 48 & 0.02 \\
\hline Female & 42 & 38 & 43 & 53 & \\
\hline \multicolumn{6}{|l|}{ Hemoglobinopathy (\%) } \\
\hline SS & 82 & 83 & 81 & 83 & 0.94 \\
\hline Other & 18 & 17 & 19 & 17 & \\
\hline $\begin{array}{l}\text { Mean age at first episode of acute chest } \\
\text { syndrome ( } \mathrm{yr})\end{array}$ & 13.8 & 5.4 & 14.6 & 30.2 & $<0.001$ \\
\hline \multicolumn{6}{|l|}{ Medical history (\%) } \\
\hline Vaso-occlusive event & 80 & 72 & 85 & 89 & $<0.001$ \\
\hline Transfusion & 74 & 63 & 84 & 86 & $<0.001$ \\
\hline Acute chest syndrome or pneumonia & 67 & 63 & 66 & 76 & 0.03 \\
\hline Prophylactic antibiotic therapy & 57 & 81 & 51 & 13 & $<0.001$ \\
\hline Major surgery & 40 & 26 & 48 & 61 & $<0.001$ \\
\hline Neurologic disease & 16 & 10 & 17 & 29 & $<0.001$ \\
\hline Sleep apnea & 14 & 14 & 17 & 11 & 0.41 \\
\hline Red-cell antibodies & 12 & 7 & 14 & 21 & $<0.001$ \\
\hline Aseptic necrosis or fracture & 12 & 5 & 11 & 26 & $<0.001$ \\
\hline Asthma & 11 & 14 & 9 & 5 & 0.01 \\
\hline Smoking & 10 & 0 & 4 & 36 & $<0.001$ \\
\hline $\begin{array}{l}\text { Renal disease or urinary tract } \\
\text { infection }\end{array}$ & 7 & 3 & 7 & 14 & $<0.001$ \\
\hline Chronic transfusion therapy & 5 & 5 & 5 & 7 & 0.64 \\
\hline Cardiac disease & 4 & 1 & 3 & 12 & $<0.001$ \\
\hline Chronic lung disease & 4 & 3 & 4 & 5 & 0.46 \\
\hline Pulmonary edema & 4 & 1 & 3 & 9 & $<0.001$ \\
\hline Clubbing & 2 & 1 & 0 & 5 & 0.002 \\
\hline Deep-vein thrombosis & 1 & $<1$ & 0 & 3 & 0.01 \\
\hline Tuberculosis & $<1$ & 0 & 0 & 1 & 0.20 \\
\hline \multicolumn{6}{|l|}{ Reason for current admission (\%) } \\
\hline Acute chest syndrome & 52 & 61 & 46 & 42 & $<0.001$ \\
\hline Other & 48 & 39 & 54 & 58 & \\
\hline \multicolumn{6}{|l|}{$\begin{array}{l}\text { Symptoms at diagnosis of acute chest } \\
\text { syndrome }(\%)\end{array}$} \\
\hline Fever & 80 & 86 & 78 & 70 & $<0.001$ \\
\hline Cough & 62 & 69 & 58 & 54 & 0.006 \\
\hline Chest pain & 44 & 27 & 67 & 55 & $<0.001$ \\
\hline Tachypnea & 45 & 47 & 47 & 39 & 0.27 \\
\hline Shortness of breath & 41 & 31 & 44 & 58 & $<0.001$ \\
\hline Pain in arms and legs & 37 & 22 & 44 & 59 & $<0.001$ \\
\hline Abdominal pain & 35 & 38 & 36 & 29 & 0.24 \\
\hline Rib or sternal pain & 21 & 14 & 26 & 30 & $<0.001$ \\
\hline Reactive airway disease & 13 & 17 & 12 & 6 & 0.01 \\
\hline Neurologic dysfunction & 4 & 3 & 3 & 7 & 0.11 \\
\hline Cyanosis & 2 & 1 & 3 & 3 & 0.24 \\
\hline Heart failure & 1 & 2 & 1 & 1 & 0.49 \\
\hline
\end{tabular}

*Because of rounding, percentages may not total 100. Data on one patient were excluded because the patient's birth date was not known.

$\dagger P$ values were calculated by chi-square analyses.

$\ddagger$ Other reasons included a vaso-occlusive event, anemia, fever, infection, gastrointestinal or abdominal pain, asthma, urologic and orthopedic conditions, heart failure, and surgery.

The mean forced expiratory volume in one second during the acute phase of the syndrome was 53 percent of the predicted value. Sixty-one percent of patients were treated with bronchodilators, and 20 percent of these patients had clinical improvement (defined as an increase of 15 percent in forced expiratory volume in one second, expressed as a percentage of the predicted value). Among those with im- provement, the mean forced expiratory volume in one second was initially 41 percent of the predicted value and increased to 52 percent, a 27 percent improvement.

Seventy-two percent of patients received transfusions (Table 2). The mean number of transfusions per patient was 1.6, and the mean number of units per patient was 3.2. Sixty-eight percent of patients 
Table 2. Characteristics and Treatment of the Patients DURING HoSPITALIZATION.*

\begin{tabular}{|c|c|c|c|c|c|}
\hline \multirow[t]{2}{*}{ VARIABLE } & \multirow[t]{2}{*}{$\begin{array}{c}\text { AlL } \\
\text { PATIENTS } \\
(\mathrm{N}=\mathbf{5 3 7})\end{array}$} & \multicolumn{3}{|c|}{$\begin{array}{l}\text { Age at First Episode of } \\
\text { Acute Chest Syndrome }\end{array}$} & \multirow[t]{2}{*}{$\underset{\text { Valuet }}{\mathbf{P}}$} \\
\hline & & $\begin{array}{c}0-9 \text { YR } \\
(\mathrm{N}=264)\end{array}$ & $\begin{array}{l}10-19 \text { YR } \\
(\mathrm{N}=145)\end{array}$ & $\begin{array}{l}\geqslant 20 \mathrm{YR} \\
(\mathrm{N}=128)\end{array}$ & \\
\hline \multicolumn{6}{|l|}{ Findings on physical examination } \\
\hline Respiratory rate $>30 / \mathrm{min}(\%)$ & 67 & 84 & 61 & 38 & $<0.001$ \\
\hline Mean peak respiratory rate $/ \mathrm{min}$ & 38 & 44 & 36 & 30 & $<0.001$ \\
\hline Mean peak temperature $\left({ }^{\circ} \mathrm{C}\right)$ & 38.9 & 39.0 & 39.0 & 38.8 & 0.02 \\
\hline Rales (\%) & 76 & 75 & 74 & 81 & 0.36 \\
\hline Wheezing (\%) & 26 & 33 & 23 & 16 & $<0.001$ \\
\hline Nasal flaring (\%) & 26 & 37 & 19 & 10 & $<0.001$ \\
\hline $\begin{array}{l}\text { Mean no. of lobes involved at } \\
\text { diagnosis }\end{array}$ & 1.7 & 1.7 & 1.7 & 1.6 & 0.65 \\
\hline Effusion at diagnosis (\%) & 36 & 34 & 47 & 27 & 0.006 \\
\hline \multicolumn{6}{|l|}{ Base-line laboratory values } \\
\hline Mean hemoglobin $(\mathrm{g} / \mathrm{dl})$ & 7.7 & 7.5 & 8.1 & 7.9 & 0.01 \\
\hline $\begin{array}{l}\text { Mean decrease in hemoglobin } \\
\text { from steady-state value }(\mathrm{g} / \mathrm{dl})\end{array}$ & 0.78 & 0.73 & 0.68 & 0.98 & 0.42 \\
\hline Mean white-cell count $\left(\right.$ per $\left.\mathrm{mm}^{3}\right)$ & 23,000 & 25,000 & 22,000 & 20,000 & $<0.001$ \\
\hline $\begin{array}{l}\text { Mean partial pressure of arterial } \\
\text { oxygen at diagnosis }(\mathrm{mm} \mathrm{Hg}) \ddagger\end{array}$ & 70 & 71 & 68 & 71 & 0.50 \\
\hline Mean oxygen saturation $(\%) \$$ & 92 & 92 & 92 & 93 & 0.82 \\
\hline $\begin{array}{l}\text { Mean maximal no. of lobes involved } \\
\text { during hospitalization }\end{array}$ & 2.2 & 2.2 & 2.1 & 2.3 & 0.45 \\
\hline Upper lobes (\%) & 34 & 36 & 29 & 36 & 0.34 \\
\hline Lower lobes (\%) & 92 & 89 & 93 & 96 & 0.04 \\
\hline Middle lobes (\%) & 40 & 43 & 34 & 41 & 0.19 \\
\hline Effusion during hospitalization (\%) & 55 & 52 & 71 & 41 & $<0.001$ \\
\hline \multicolumn{6}{|l|}{ Treatment $(\%)$} \\
\hline Erythromycin & 87 & 89 & 89 & 81 & 0.07 \\
\hline Cephalosporin & 92 & 93 & 94 & 88 & 0.17 \\
\hline Other type of antibiotic & 37 & 28 & 33 & 61 & $<0.001$ \\
\hline Oxygen & 85 & 80 & 90 & 88 & 0.02 \\
\hline Transfusion & 72 & 73 & 81 & 61 & $<0.001$ \\
\hline Bronchodilator & 61 & 69 & 62 & 44 & $<0.001$ \\
\hline Mechanical ventilation & 13 & 10 & 10 & 22 & 0.002 \\
\hline \multicolumn{6}{|l|}{ Complications (\%) } \\
\hline Vaso-occlusive event & 64 & 47 & 78 & 82 & $<0.001$ \\
\hline Abdominal pain & 45 & 46 & 46 & 39 & 0.36 \\
\hline Pulmonary event $\|$ & 14 & 11 & 10 & 23 & 0.004 \\
\hline Neurologic event & 11 & 7 & 10 & 22 & $<0.001$ \\
\hline Cardiac event** & 5 & 4 & 5 & 9 & 0.07 \\
\hline Gastrointestinal event†† & 3 & 2 & 3 & 8 & 0.005 \\
\hline Renal event & 2 & $<1$ & 1 & 8 & $<0.001$ \\
\hline Death & 3 & $<1$ & 2 & 9 & $<0.001$ \\
\hline $\begin{array}{l}\text { Mean duration of hospitalization } \\
\text { (days) } \ddagger \ddagger\end{array}$ & 10.5 & 9.7 & 10.0 & 12.8 & 0.04 \\
\hline
\end{tabular}

*Data on one patient were excluded because the patient's birth date was not known.

$\dagger \mathrm{P}$ values were calculated by chi-square analyses.

$\ddagger$ The partial pressure of arterial oxygen was measured while the patient was breathing room air. SOxygen saturation was measured by pulse oximetry while the patient was breathing room air.

TThis category included any painful episode that occurred during hospitalization.

$\|$ This category included respiratory failure, pneumothorax, and empyema requiring thoracentesis. ** This category included arrhythmia, congestive heart failure, hypertension, and hypotension. $\dagger †$ This category included gastrointestinal hemorrhage, ileus, and bowel infarction.

$\ddagger \ddagger$ This category included all days of hospitalization, even those that occurred before the diagnosis of the acute chest syndrome in the case of patients who were admitted for reasons other than the syndrome. 
received simple transfusions, and 64 percent received phenotypically matched red cells. Oxygenation significantly improved with transfusion. On average, the partial pressure of arterial oxygen while the patients were breathing room air was $63 \mathrm{~mm} \mathrm{Hg}$ before transfusion and $71 \mathrm{~mm} \mathrm{Hg}$ after transfusion $(\mathrm{P}<0.001)$. Similarly, oxygen saturation increased from 91 percent to 94 percent with transfusion $(\mathrm{P}<0.001)$. When we analyzed only patients who had hypoxia before transfusion (defined as an oxygen saturation of less than 91 percent), the values increased from 86 percent to 93 percent $(\mathrm{P}<0.001)$. Both simple and exchange transfusion resulted in similar improvements in oxygenation. Overall, 2.4 percent of patients had a new red-cell antibody, including l percent of the patients who received phenotypically matched units and 5 percent of those who received standard transfusions $(\mathrm{P}=0.02)$.

The mean hospital stay was 10.5 days. Cox proportional-hazards regression analysis of 19 covariates that were significant on univariate analysis showed that after adjustment for the remaining factors, an age of 20 years or more, a history of vaso-occlusive events, a platelet count of 0 to 199,000 per cubic millimeter at diagnosis, pain in the arms and legs at presentation, extensive radiographic abnormalities, evidence of effusion on radiographic analysis, fever, treatment by transfusion, and respiratory failure were independently associated with prolonged hospitalization (Table 3).

\section{Complications}

Older patients (particularly those who were 20 years of age or older) were more likely to have complications and to die during hospitalization (Table 2). Respiratory failure was documented in 13 percent of patients. To identify predictors of respiratory failure that were present at the time of diagnosis, we developed a multivariable logistic-regression model that included age and 10 variables that were significant on univariate analyses. Radiographic evidence of extensive lobar involvement, a platelet count of 0 to 199,000 per cubic millimeter at diagnosis, and a history of cardiac disease remained independent predictors of respiratory failure (Table 3 ).

Neurologic events occurred in 11 percent of patients. The most common were altered mental status (in 56 percent), seizures (11 percent), and neuromuscular abnormalities ( 8 percent). Anoxic brain injury occurred in three patients, central nervous system hemorrhage in three, and infarction in three. Respiratory failure developed in 46 percent of patients with neurologic complications; 92 percent of these patients underwent transfusion, and 23 percent died. The mean hospital stay for these patients was 19.5 days, as compared with 9.4 days for the remainder of the patients $(\mathrm{P}=0.008)$. Multivariable logistic-regression analysis of 11 variables that were significant on univariate analysis showed that only the platelet count remained an independent predictor of neurologic complications during hospitalization (Table 3 ). Those with relative thrombocytopenia (defined as a platelet count of less than 200,000 per cubic millimeter) were at the greatest risk for neurologic complications.

Complications occurred in 13 percent of all bronchoscopic procedures (28 of 219). Half the complications consisted of a transient decline in oxygen saturation. Laryngospasm occurred in 10 patients, and pneumothorax developed in 2 patients, both of whom had had the acute respiratory distress syndrome before the bronchoscopy. Eight patients underwent intubation because of bronchoscopic complications. As compared with the patients who underwent bronchoscopy without incident, the patients who had complications were more likely to present with dyspnea (61 percent vs. 36 percent, $\mathrm{P}=0.04$ ) and higher peak respiratory rates (mean, 47 vs. 41 per minute; $\mathrm{P}=0.03$ ).

Eighteen patients died. The primary causes of death were respiratory failure from pulmonary emboli (bone marrow, fat, or thrombotic) in six patients and bronchopneumonia in six. The causes of death in the remaining patients were pulmonary hemorrhage, cor pulmonale, hypovolemic shock from splenic sequestration, overwhelming sepsis, intracranial hemorrhage, and seizure. Overall, infection was a contributing factor in 10 deaths. The organisms identified included Streptococcus pneumoniae, Escherichia coli, Haemophilus influenzae, legionella, cytomegalovirus, Staphylococcus aureus, and chlamydia.

\section{Causes of the Acute Chest Syndrome}

The causes of the acute chest syndrome are given in Table 4. A specific cause (either pulmonary fat embolism or an infectious agent) was identified in 256 (38 percent) episodes. After the exclusion of episodes with incomplete data, a specific cause was identified in 70 percent of episodes. Pulmonary infarction was presumed to be the cause in 16 percent of episodes in which there were complete data but no cause could be identified.

Bronchoscopic or sputum samples were obtained for analysis of fat embolisms in 72 percent of episodes. The results for 15 percent of the bronchoscopic specimens could not be interpreted. The majority of these specimens contained large quantities of inflammatory cells that made it impossible to identify pulmonary macrophages. A significantly larger percentage of sputum samples were uninterpretable (42 percent, $\mathrm{P}<0.001$ ), in most cases because of contamination with epithelial cells from the oropharynx or an inflammatory exudate.

Of the 27 different pathogens identified, C. pneumoniae was the most frequent, followed by M. pneumoniae and respiratory syncytial virus (Table 5). Parvovirus was isolated from a bronchial sample in 10 
Table 3. Overall Predictors of Prolonged Hospitalization, Respiratory Failure, and Neurologic Complications among Patients with the Acute Chest Syndrome.*

RISK FACTOR

Prolonged hospitalization

Age

0 to $9.9 \mathrm{yr}$

10.0 to $19.9 \mathrm{yr}$

$\geqslant 20 \mathrm{yr}$

History of vaso-occlusive event

Pain in arms and legs on presentation

Platelet count at diagnosis

0 to $199,000 / \mathrm{mm}^{3}$

200,000 to $399,000 / \mathrm{mm}^{3}$

$\geqslant 400,000 / \mathrm{mm}^{3}$

Fever during hospitalization

Radiographic evidence of effusion during hospitalization

No. of involved lobes on radiographic examination during hospitalization

0 to 1

2 to 3

$\geqslant 4$

Transfusion therapy during hospitalization Respiratory failure during hospitalization $\ddagger$
Hazard Ratio (95\% Cl) $\dagger$ P Value

1.0

$1.20(0.90-1.60) \quad 0.22$

$0.62(0.43-0.91) \quad 0.01$

$0.71(0.54-0.92) \quad 0.02$

$0.70(0.53-0.93) \quad 0.01$

1.0

$1.40(1.02-1.96) \quad 0.04$

$1.40(0.95-1.90) \quad 0.09$

$0.66(0.45-0.95) \quad 0.03$

$0.67(0.50-0.91) \quad 0.009$

1.0

$0.68(0.49-0.93) \quad 0.02$

$0.43(0.24-0.78) \quad 0.005$

$0.62(0.47-0.81)<0.001$

$0.41(0.27-0.64)<0.001$

Percent

REQUiRING

Mechanical

Ventilation

Odds Ratio (95\% Cl)§ P Value

Respiratory failure $\ddagger$

History of cardiac disease No

Yes

$12 \quad 1.0$

No. of lobes involved on

1.0

0.002

radiographic examination

0 to 1

2 to 3

Platelet count at diagnosis

0 to $199,000 / \mathrm{mm}^{3}$

200,000 to $399,000 / \mathrm{mm}^{3}$

$\geqslant 400,000 / \mathrm{mm}^{3}$

$3 .-1.0$

$11 \quad 2.2(1.0-4.6) \quad 0.04$

$9.0(2.5-32.7)<0.001$

$23 \quad 1.0$

$11 \quad 0.9(0.37-2.1) \quad 0.75$

Percent With

Neurologic

Complications Odd Ratio $(95 \%$ Cl) $\$$ P Value

Neurologic complications

Platelet count at diagnosis

0 to $199,000 / \mathrm{mm}^{3}$

200,000 to $399,000 / \mathrm{mm}^{3}$

$\geqslant 400,000 / \mathrm{mm}^{3}$

31

1.0

$0.3(0.14-0.68)$

$0.2(0.07-0.55)$

0.004

0.002

* Only risk factors that were significant on multivariable regression analysis are included CI denotes confidence interval.

†Cox regression analysis was used, with data on patients who died censored at the time of death.

$\ddagger$ Respiratory failure was defined as the need for mechanical ventilation.

\$Odds ratios are given for risk factors that were significant on multivariable logistic regression. Only risk factors that were present at the time of diagnosis were included in the models. 
Table 4. Causes of the Acute Chest Syndrome.*

\begin{tabular}{|c|c|c|c|c|}
\hline \multirow[t]{3}{*}{ Cause } & $\begin{array}{l}\text { ALL EPISODES } \\
(\mathbf{N}=\mathbf{6 7 0})\end{array}$ & \multicolumn{3}{|c|}{ Age at Episode of Acute Chest Syndrome } \\
\hline & & $\begin{array}{c}0-9 \text { YR } \\
(\mathrm{N}=329)\end{array}$ & $\begin{array}{l}10-19 \text { YR } \\
(\mathrm{N}=188)\end{array}$ & $\begin{array}{l}\geqslant 20 \mathrm{YR} \\
(\mathrm{N}=153)\end{array}$ \\
\hline & \multicolumn{4}{|c|}{ no. of episodes (\%) } \\
\hline Fat embolism, with or without infection $\dagger$ & $59(8.8)$ & 24 & 16 & 19 \\
\hline Chlamydia & $48(7.2)$ & 19 & 15 & 14 \\
\hline Mycoplasma & $44(6.6)$ & 29 & 7 & 8 \\
\hline Virus & $43(6.4)$ & 36 & 5 & 2 \\
\hline Bacteria & $30(4.5)$ & 13 & 5 & 12 \\
\hline Mixed infections & $25(3.7)$ & 16 & 6 & 3 \\
\hline Legionella & $4(0.6)$ & 3 & 0 & 1 \\
\hline Miscellaneous infections & $3(0.4)$ & 0 & 3 & 0 \\
\hline Infarction $\|$ & $108(16.1)$ & 50 & 43 & 15 \\
\hline Unknown** & $306(45.7)$ & 139 & 88 & 79 \\
\hline
\end{tabular}

*Data on one episode were excluded because the patient's birth date was not known.

$\dagger$ Nineteen of the episodes of pulmonary fat embolism were associated with infectious pathogens.

$\ddagger$ This category included episodes in which chlamydia alone was identified but not episodes involving mixed infections or pulmonary fat embolism.

\$This category included episodes in which only Mycoplasma pneumoniae or Mycoplasma hominis was identified, but not episodes involving mixed infections, Mycobacterium tuberculosis, or pulmonary fat embolism.

IThis category included two cases of tuberculosis and one case of Mycobacterium avium complex infection.

||A pulmonary infarction was presumed to have occurred during episodes in which the results of the analysis for pulmonary fat embolism, bacterial studies, viral-isolation studies, and serologic tests were complete and were all negative.

** The cause of episodes for which some or all of the diagnostic data were incomplete and no etiologic agent was identified was considered to be unknown.

episodes. Severe reticulocytopenia was present in 5 of these 10 episodes. In total, 249 pathogens were identified in 216 episodes. A single infectious pathogen was identified in 172 episodes, multiple pathogens were identified in 25 episodes, and fat embolism was diagnosed together with an infectious agent in 19 episodes.

\section{Comparison of Pulmonary Fat Embolism, Infection, and Infarction}

We compared the characteristics of 53 patients with fat embolism as a cause of a first episode of the acute chest syndrome, 157 with infection as a cause, and 82 with infarction as the presumed cause. More patients in the fat-embolism group than in the infection group or the infarction group were 20 years of age or older (30 percent vs. 22 percent and 13 percent, $\mathrm{P}=0.003)$. The patients in the fat-embolism group also had a lower mean oxygen saturation at presentation (89 percent vs. 94 percent and 91 percent, $\mathrm{P}=0.02$ ) and were more likely to have upperlobe infiltrates during hospitalization ( 45 percent vs. 38 percent and 24 percent, $\mathrm{P}=0.04)$. The overall rates of complications were similar in the three groups, except for a higher incidence of vaso-occlusive events in the fat-embolism group (74 percent vs. 54 percent and 68 percent, $\mathrm{P}=0.02)$.

\section{Comparison of Chlamydia and Mycoplasma Infections}

We also compared the characteristics of the patients who were infected with the two most common pathogens. As compared with patients with mycoplasma infections, patients with chlamydia infections were older (mean age, 17.8 vs. 11.3 years; $\mathrm{P}=0.02$ ), were less likely to be taking prophylactic antibiotics (43 percent vs. 77 percent, $\mathrm{P}=0.006$ ), and were more likely to have a vaso-occlusive event during hospitalization (65 percent vs. 39 percent, $\mathrm{P}=0.04$ ). At diagnosis, patients with chlamydia infections had higher mean hemoglobin levels than did patients with mycoplasma infections ( 8.0 vs. 7.0 g per deciliter, $\mathrm{P}=0.03$ ).

In seven episodes $M$. hominis was the only agent identified. The patients with $M$. hominis infections were older than those with $M$. pneumoniae infections (mean age, 19.6 vs. 10.2 years) but were similar in other respects.

\section{DISCUSSION}

Although there is an increased awareness that the acute chest syndrome is the leading cause of death 
Table 5. Infectious Pathogens Isolated IN 671 EPISODES OF THE ACUTE CHest SYNDROME.*

\begin{tabular}{|c|c|}
\hline Pathogen & $\begin{array}{c}\text { No. OF } \\
\text { EPISODES }\end{array}$ \\
\hline Chlamydia pneumoniae & 71 \\
\hline Mycoplasma pneumoniae & 51 \\
\hline Respiratory syncytial virus & 26 \\
\hline Coagulase-positive Staphylococcus aureus & 12 \\
\hline Streptococcus pneumoniae & 11 \\
\hline Mycoplasma hominis & 10 \\
\hline Parvovirus & 10 \\
\hline Rhinovirus & 8 \\
\hline Parainfluenzavirus & 6 \\
\hline Haemophilus influenzae & 5 \\
\hline Cytomegalovirus & 4 \\
\hline Influenza A virus & 4 \\
\hline Legionella pneumophila & 4 \\
\hline Escherichia coli & 3 \\
\hline Epstein-Barr virus & 3 \\
\hline Herpes simplex virus & 3 \\
\hline Pseudomonas species & 3 \\
\hline Adenovirus & 2 \\
\hline Branhamella species & 2 \\
\hline Echovirus & 2 \\
\hline Beta-hemolytic streptococcus & 2 \\
\hline Mycobacterium tuberculosis & 2 \\
\hline Enterobacter species & 1 \\
\hline Klebsiella pneumoniae & 1 \\
\hline Mycobacterium avium complex & 1 \\
\hline Salmonella species & 1 \\
\hline Serratia marcescens & 1 \\
\hline Total & 249 \\
\hline
\end{tabular}
the acute chest syndrome are included.

in patients with sickle cell disease, the diagnosis is often delayed, the optimal treatment is unknown, and the cause is usually not determined. The longer patients with sickle cell disease live, the higher the frequency of recurrent pulmonary disease and resultant chronic lung disease. ${ }^{21}$ Despite the young age of our patients, more than two thirds had a history of the acute chest syndrome, and many had multiple episodes during the study.

The symptoms at presentation were age-dependent; wheezing, cough, and fever were most common among patients who were younger than 10 years of age, whereas pain in the arms and legs and dyspnea were more common among the adults. ${ }^{22}$ Almost half the patients in whom the acute chest syndrome developed were admitted for other reasons, including pain, and had radiographic and clinical symptoms within three days after hospitalization. Clearly, pain is a prodrome of the acute chest syndrome, ${ }^{22,23}$ and a single physical examination or radiograph may not be adequate for early diagnosis.
Laboratory values worsened after the diagnosis of the syndrome despite aggressive intervention. As in previous studies, we found that involvement of the lower lobes predominated, ,9,22 radiographic abnormalities progressed, and oxygenation and hemoglobin levels declined. These findings indicate that serial monitoring is necessary.

The average length of hospitalization was more than 10 days and was longer than that reported in previous studies. ${ }^{8,9}$ An older age, pain in the arms and legs at presentation, fever, a low platelet count at diagnosis, extensive radiographic abnormalities, transfusion therapy, and respiratory failure were associated with prolonged hospitalization. At the time of diagnosis of the acute chest syndrome, patients who went on to have respiratory failure were more likely to have a history of cardiac disease, to have four or more lobes affected, and to have platelet counts of 0 to 199,000 per cubic millimeter at base line. In the general population, similar findings have been found to be predictive of the severity of pneumonia, the acute respiratory distress syndrome, and the acute multiorgan-failure syndrome. ${ }^{24-26}$

There is a strong relation between the acute chest syndrome and the occurrence of neurologic complications. Neurologic complications developed in 22 percent of the adults in our study. In nearly half these patients, respiratory failure subsequently developed. A recent history of a pulmonary event is the nonneurologic risk factor that is the most highly predictive of stroke. ${ }^{27}$ The mechanism most likely involves sudden decreases in oxygenation in the vascular bed of the central nervous system. ${ }^{27,28}$ Although our statistical model included only a small number of neurologic events, the occurrence of relative thrombocytopenia has been associated with neurologic ischemic insults and reflects the presence of hypoxia, tissue damage, and platelet consumption. ${ }^{29,30}$ In addition, fat embolism and infection with chlamydia or mycoplasma may also play a direct part in brain injury. ${ }^{31,32}$

Our study evaluated interventions such as transfusions, bronchodilators, antibiotics, and mechanical ventilation. Almost three quarters of the patients received transfusions because of a worsening clinical course. Both exchange and simple transfusions improved oxygenation, providing evidence to support studies that demonstrate that limited transfusions alleviate organ dysfunction. ${ }^{33-35}$ The use of phenotypically matched units resulted in a 1 percent rate of alloimmunization, which is lower than the rate of 7 percent that is associated with standard transfusions, ${ }^{33}$ and pulmonary function improved with bronchodilator therapy. The 81 percent rate of recovery after mechanical ventilation is better than the rate among patients with the acute respiratory distress syndrome. ${ }^{36}$

The cause of the acute chest syndrome was established in 38 percent of episodes, and pulmonary infarc- 
tion was the presumed cause in another 16 percent. In contrast to prior studies, in which specific causes were seldom identified, ${ }^{2,22}$ infection and emboli were common causes in our study. We examined bronchoalveolar-lavage fluid because of previous reports of the successful identification of bacterial pathogens and pulmonary fat embolism in such specimens. ${ }^{10-12,37,38}$ Bronchoscopy produced higher-quality samples than did the collection of sputum, although this procedure was associated with a risk of complications. However, in 85 percent of samples, adequate material was collected and the diagnostic yields were high.

We identified a large number of organisms that have not usually been associated with the acute chest syndrome. Chlamydia was the most common isolate and was associated with an increased rate of vaso-occlusive events, although the rate of infection with this organism was similar to that in the general population..$^{39,40}$ Mycoplasma and viral pneumonia, including that caused by parvovirus, occurred in all age groups, but predominated among young children. ${ }^{6} \mathrm{We}$ also found that M. hominis was responsible for seven episodes of the acute chest syndrome and legionella for four. These organisms have not been considered causes of the syndrome, but they should be.

As reported in previous studies, ${ }^{11,12}$ pulmonary fat embolism was common in our study and the clinical course of patients with this cause varied. Although the catalyst of the syndrome may be pulmonary fat embolism or infection, these events precipitate sickling, regional hypoxia, and further ischemic damage.41-44 An environment ideal for sickle cell-related injury is created by altering cellular adhesive molecules, damaging the vascular endothelium, and stimulating cytokines. $11,23,41,43-45$

In order to minimize lung injury in patients with sickle cell disease, a comprehensive plan aimed at both the catalyst and the host response is needed. Patients should receive the influenza and pneumococcal vaccines, and they should be evaluated for respiratory syncytial virus vaccine. Those admitted for painful crises should be considered to be in the prodromal phase of the acute chest syndrome; they require incentive spirometry and daily monitoring for pulmonary disease.

Once the acute chest syndrome has been diagnosed, broad-spectrum antibiotics, including a macrolide, are required. Airway hyperreactivity should be assumed to be present, even if the patient is not wheezing, and treatment with bronchodilators should be initiated. Routine, early transfusions are indicated for patients at high risk for complications, including adults and those who have a history of cardiac disease and severe pain in the arms and legs at presentation. Those who present with severe anemia, thrombocytopenia, or both and multilobar pneumonia should receive a transfusion before respiratory distress develops. In most patients with anemia, treatment with leu- kocyte-depleted, matched, simple transfusions is safe and effective.

Bronchoscopy is recommended in patients with no response to initial therapy because of the potential for organisms to be missed by analysis of sputum samples. Preliminary reports suggest that corticosteroids and nitric oxide are beneficial in severe cases that have not responded to other treatments. ${ }^{45,46}$ Given the high rate of success with mechanical ventilation in our study, aggressive ventilatory support, including extracorporeal membrane oxygenation, may be necessary. After recovery, patients must be evaluated for lung injury. Hydroxyurea, transfusion therapy, or bone marrow transplantation may be indicated in patients with recurrent events.

Supported by grants (HL-20985, HL-99-016, and M-01RR0127l) from the National Institutes of Health.

We are indebted to Shanda Robertson and Dana Kelly for data management, to Karen Seth and Christy Andrews for assistance in the preparation of the manuscript, to Dr. Julias Schachter for performing chlamydia cultures and determining antibody titers, and to Dr. William Klitz and Dr. Dennis Black for statistical support.

\section{APPENDIX}

The following investigators also participated in the National Acute Chest Syndrome Study Group: C. Daeschner (East Carolina University), P. Groncy (Memorial Miller Children's Hospital), R. Iyer (University of Mississippi), T. Kinney (Duke University Medical Center), M. Koshy (University of Illinois), W. Rackoff (Indiana University Medical Center), C. Pegelow (University of Miami), H. Hume (St. Justine Hospital), J. Parke (Carolinas Medical Center), L. McMahon (Boston Medical Center), L. Benjamin and M. Bestak (Albert Einstein College of Medicine-Montefiore Hospital), F. Little and Y. Ming-Yang (University of South Alabama), P. Waldron (University of Virginia), D. Wethers and G. Ramirez (St. Luke's-Roosevelt Hospital), N. Grossman (Columbus Children's Hospital), S. Embury and W. Mentzer (San Francisco General Hospital), M. Grossi (Children's Hospital of Buffalo), S. Claster (Summit Medical Center), L. Guarini (Interfaith Medical Center), M. Koehler (Children's Hospital of Pittsburgh), J. Eckman and T. Adamkiewicz (Emory University), E. Lowenthal (University of Alabama at Birmingham), P. Swerdlow (Medical College of Virginia), and C. Johnson (University of Southern California Medical Center).

\section{REFERENCES}

1. Vichinsky E. Comprehensive care in sickle cell disease: its impact on morbidity and mortality. Semin Hematol 1991;28:220-6.

2. Castro $\mathrm{O}$, Brambilla DJ, Thorington $\mathrm{B}$, et al. The acute chest syndrome in sickle cell disease: incidence and risk factors: the Cooperative Study of Sickle Cell Disease. Blood 1994;84:643-9.

3. Platt OS, Brambilla DJ, Rosse WF, et al. Mortality in sickle cell disease: life expectancy and risk factors for early death. N Engl J Med 1994;330: 1639-44.

4. Castro O. Systemic fat embolism and pulmonary hypertension in sickle cell disease. Hematol Oncol Clin North Am 1996;10:1289-303.

5. Bellet PS, Kalinyak KA, Shukla R, Gelfand MJ, Rucknagel DL. Incentive spirometry to prevent acute pulmonary complications in sickle cell diseases. N Engl J Med 1995;333:699-703.

6. Lowenthal EA, Wells A, Emanuel PD, Player R, Prchal JT. Sickle cell acute chest syndrome associated with parvovirus B19 infection: case series and review. Am J Hematol 1996;51:207-13.

7. Miller ST, Hammerschlag MR, Chirgwin K, et al. Role of Chlamydia pneumoniae in acute chest syndrome of sickle cell disease. J Pediatr 1991; 118:30-3.

8. Poncz M, Kane E, Gill FM. Acute chest syndrome in sickle cell disease: etiology and clinical correlates. J Pediatr 1985;107:861-6.

9. Sprinkle RH, Cole T, Smith S, Buchanan GR. Acute chest syndrome in children with sickle cell disease: a retrospective analysis of 100 hospitalized cases. Am J Pediatr Hematol Oncol 1986;8:105-10.

10. Kirkpatrick MB, Haynes J Jr, Bass JB Jr. Results of bronchoscopically 
obtained lower airway cultures from adult sickle cell disease patients with the acute chest syndrome. Am J Med 1991;90:206-10.

11. Vichinsky E, Williams R, Das M, et al. Pulmonary fat embolism: a distinct cause of severe acute chest syndrome in sickle cell anemia. Blood 1994;83:3107-12.

12. Godeau B, Schaeffer A, Bachier D, et al. Bronchoalveolar lavage in adult sickle cell patients with acute chest syndrome: value for diagnostic assessment of fat embolism. Am J Respir Crit Care Med 1996;153:1691-6. 13. Hutchinson RM, Merrick MV, White JM. Fat embolism in sickle cell disease. J Clin Pathol 1973;26:620-2.

14. Landry ML, Hsiung GD. Primary isolation of viruses. In: Specter S, Lancz G, eds. Clinical virology manual. 2nd ed. New York: Elsevier Science Publishing, 1992:43-69.

15. Waites KB, Taylor-Robinson D. Mycoplasma and Ureaplasma. In: Murray PR, ed. Manual of clinical microbiology. 7th ed. Washington, D.C.: ASM Press, 1999:782-806.

16. Lennette ET, Lennette DA. Immune adherence hemagglutination. In Specter S, Lancz G, eds. Clinical virology manual. 2nd ed. New York: Elsevier Science Publishing, 1992:251-61.

17. Kajigaya $S$, Shimada T, Fujita S, Young NS. A genetically engineered cell line that produces empty capsids of B19 (human) parvovirus. Proc Nat Acad Sci U S A 1989;86:7601-5.

18. Lennette ET. Epstein-Barr virus. In: Murray PR, ed. Manual of clinical microbiology. 7th ed. Washington, D.C.: ASM Press, 1999:912-8.

19. Schachter J. Chlamydiae. In: Balows A, Hausler WJ Jr, Hermann KL Isenberg HD, Shadomy HJ, eds. Manual of clinical microbiology. 5th ed. Washington, D.C.: ASM Press, 1991:1045-53.

20. Lietman T, Brooks D, Moncada J, Schachter J, Dawson C, Dean D.

Chronic follicular conjunctivitis associated with Chlamydia psittaci or Chlamydia pneumoniae. Clin Infect Dis 1998;26:1335-40.

21. Powars D, Weidman JA, Odom-Maryon T, Niland JC, Johnson C.

Sickle cell chronic lung disease: prior morbidity and the risk of pulmonary failure. Medicine (Baltimore) 1988;67:66-76.

22. Vichinsky EP, Styles LA, Colangelo LH, Wright EC, Castro O, Nickerson B. Acute chest syndrome in sickle cell disease: clinical presentation and course: Cooperative Study of Sickle Cell Disease. Blood 1997;89: 1787-92.

23. Styles LA, Schalkwijk CG, Aarsman AJ, Vichinsky EP, Lubin BH, Kuypers FA. Phospholipase A2 levels in acute chest syndrome of sickle cell disease. Blood 1996;87:2573-8

24. Bone RC, Balk R, Slotman G, et al. Adult respiratory distress syndrome: sequence and importance of development of multiple organ failure. Chest 1992;101:320-6.

25. Jacobs ER, Bone RC. Clinical indicators in sepsis and septic adult respiratory distress syndrome. Med Clin North Am 1986;70:921-32.

26. Cook DJ, Walter SD, Cook RJ, et al. Incidence of and risk factors for ventilator-associated pneumonia in critically ill patients. Ann Intern Med 1998;129:433-40.

27. Ohene-Frempong K, Weiner SJ, Sleeper LA, et al. Cerebrovascular accidents in sickle cell disease: rates and risk factors. Blood 1998;91:288-94. 28. Prohovnik I, Pavlakis SG, Piomelli S, et al. Cerebral hyperemia, stroke, and transfusion in sickle cell disease. Neurology 1989;39:344-8.

29. Tohgi H, Suzuki H, Tamura K, Kimura B. Platelet volume, aggrega- tion, and adenosine triphosphate release in cerebral thrombosis. Stroke 1991;22:17-21

30. Kohelet D, Perman M, Hanna G, Ballin A. Reduced platelet counts in neonatal respiratory distress syndrome. Biol Neonate 1990;57:334-42.

31. Cook PJ, Honeybourne D, Lip GY, Beevers DG, Wise R, Davies P. Chlamydia pneumoniae antibody titers are significantly associated with acute stroke and transient cerebral ischemia: the West Birmingham Stroke Project. Stroke 1998;29:404-10.

32. Narita M, Matsuzono $Y$, Togashi T, Kajii N. DNA diagnosis of central nervous system infection by Mycoplasma pneumoniae. Pediatrics 1992;90: 250-3.

33. Vichinsky EP, Haberkern CM, Neumayr L, et al. A comparison of conservative and aggressive transfusion regimens in the perioperative management of sickle cell disease: the Preoperative Transfusion in Sickle Cell Disease Study Group. N Engl J Med 1995;333:206-13.

34. Mallouh AA, Asha M. Beneficial effect of blood transfusion in children with sickle cell chest syndrome. Am J Dis Child 1988;142:178-82.

35. Emre U, Miller ST, Gutierez M, Steiner P, Rao SP, Rao M. Effect of transfusion in acute chest syndrome of sickle cell disease. J Pediatr 1995; 127:901-4.

36. Wyncoll DL, Evans TW. Acute respiratory distress syndrome. Lancet 1999;354:497-501.

37. Chastre J, Fagon JY, Soler P, et al. Bronchoalveolar lavage for rapid diagnosis of the fat embolism syndrome in trauma patients. Ann Intern Med 1990;130:583-8.

38. Frankel LR, Smith DW, Lewiston NJ. Bronchoalveolar lavage for diagnosis of pneumonia in the immunocompromised child. Pediatrics 1988 ; 81:785-8.

39. Bates JH, Campbell GD, Barron AL, et al. Microbial etiology of acute pneumonia in hospitalized patients. Chest 1992;101:1005-12.

40. Chirgwin K, Roblin PM, Gelling M, Hammerschlag MR, Schachter J. Infection with Chlamydia pneumoniae in Brooklyn. J Infect Dis 1991;163 757-61

41. Smolinski PA, Offermann MK, Eckman JR, Wick TM. Double-stranded RNA induces sickle erythrocyte adherence to endothelium: a potential role for viral infection in vaso-occlusive pain episodes in sickle cell anemia. Blood 1995;85:2945-50.

42. Aldrich TK, Dhuper SK, Patwa NS, et al. Pulmonary entrapment of sickle cells: the role of regional alveolar hypoxia. J Appl Physiol 1996;80: 531-9.

43. Hebbel RP, Visser MR, Goodman JL, Jacob HS, Vercellotti GM. Potentiated adherence of sickle erythrocytes to endothelium infected by virus. J Clin Invest 1987;80:1503-6.

44. Ibe BO, Morris J, Kurantsin-Mills J, Raj JU. Sickle erythrocytes induce prostacyclin and thromboxane synthesis by isolated perfused rat lungs. Am J Physiol 1997;272:L597-L602.

45. Gladwin MT, Schechter AN, Shelhamer JH, Ognibene FP. The acute chest syndrome in sickle cell disease: possible role of nitric oxide in its patho physiology and treatment. Am J Respir Crit Care Med 1999;159:1368-76. 46. Bernini JC, Rogers ZR, Sandler ES, Reisch JS, Quinn CT, Buchanan GR. Beneficial effect of intravenous dexamethasone in children with mild to moderately severe acute chest syndrome complicating sickle cell disease. Blood 1998;92:3082-9. 